\title{
Energy balance and weight regulation: genetics versus environment
}

\author{
Eric Ravussin* and Clifton Bogardus \\ Eli Lilly and Co., Clinical Diabetes and Nutrition Section, NIDDK, Phoenix, AZ 85016, USA
}

\begin{abstract}
The prevalence of obesity is reaching epidemic proportions in many industrialized countries. There is growing evidence that, even if the trigger of this epidemic is found in changes in the environment, genes are interacting with the environment to cause weight gain. Studies of twins reared apart indicate that approximately two-thirds of the variability in BMI is attributed to genetic factors. From prospective studies in Pima Indians we can ascribe $12 \%$ of the variability in BMI to metabolic rate, $5 \%$ to fat oxidation, and another probable $10 \%$ to the level of spontaneous physical activity. These data indicate that at least $40 \%$ of the variability in BMI is related to genetic factors involved in the regulation of food intake and/or volitional activity. This indicates that the most likely successful therapy for obesity may target pathways of the regulation of food intake. Similarly, an environment favouring engagement in physical activity should be promoted.
\end{abstract}

Energy balance: Weight regulation: Obesity: Genetics: Environment: Energy metabolism

Throughout the world, in parallel with industrialization, the prevalence of obesity is increasing dramatically. It is estimated that one in two Americans is overweight or obese (Flegal et al. 1998). Between the late 1970s and the early 1990 s, the prevalence of overweight subjects (BMI $\geqslant$ $25.0 \mathrm{~kg} / \mathrm{m}^{2}$ ) increased moderately from 46 to $54 \%$ in the USA. However, during the same period the prevalence of obesity (BMI $\geqslant 30.0 \mathrm{~kg} / \mathrm{m}^{2}$ ) increased from 14.5 to $22.5 \%$. The economic burden of obesity was estimated at US $\$ 99$ billion in 1995, including US $\$ 52$ billion in direct medical costs (Wolf \& Colditz, 1998).

Obesity results from a chronic disruption of energy balance. The energy balance equation states that energy stores are a reflection of the difference between energy intake and energy expenditure. Energy intake consists of food and drink consumption. Total energy expenditure can be divided into three major components: resting metabolic rate, thermic effect of food, and the energy cost of physical activity. While food intake has been difficult to measure in humans (Lichtman et al. 1992), all components of energy expenditure can be measured accurately in a respiratory chamber (Ravussin et al. 1986) and free-living physical activity can be assessed by using the doubly labelled water technique (Schoeller \& Field, 1991).

Although the pathogenesis of obesity is not completely understood (Ravussin \& Swinburn, 1992; Rosenbaum et al. 1997), in most cases excessive accumulation of fat is probably due to the interaction between genetic factors and environmental conditions. Studies of energy intake and expenditure in humans have shown that obesity is not only the result of bad behaviour, or so-called 'sloth and gluttony'. In most cases inherited metabolic characteristics, combined with unfavourable environmental conditions such as constant access to energy-dense food and minimal physical demands of daily living, cause the development of obesity. We have previously described our present westernized environment as a 'pathoenvironment' (Ravussin, 1995), whereas Egger \& Swinburn (1997) have introduced the concept of an 'obesigenic environment'. This provocative concept seems to call for a cure of the environment rather than the people living in it. However, even in this environment, so favourable to weight gain, there are many people who do not gain weight, perhaps due to a constant struggle against their nature or because of a genetic make-up that is protective against obesity.

\section{Genetics of obesity}

Studies of adoptees and twins clearly indicate that a large part of the variability in body size and body composition is attributable to genetic factors (Bouchard, 1994). In contrast, migration studies indicate an important role of the environment. Taken together these studies suggest that among different populations the prevalence of obesity is largely determined by environmental factors. However, among individuals from the same population, living in a given environment, the variability in body size and body composition is mostly related to genetically determined response to that environment. Studies of twins reared apart indicate that approximately two-thirds of the variability in 

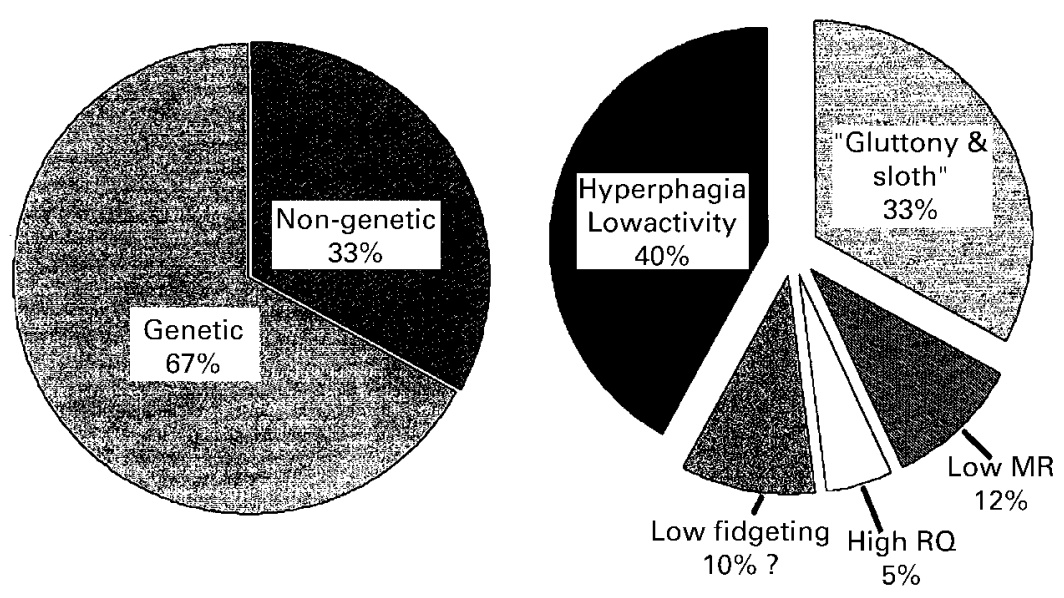

Fig. 1. (a) Studies of monozygotic twins reared apart (see Table 1) indicate that approximately one-third of the variability in BMI is attributable to non-genetic factors and two-thirds to genetic factors. (b) Breakdown of the genetic part of the variability in BMI into effects of metabolic rate (MR), respiratory quotient (RQ), spontaneous physical activity (fidgeting) and hyperphagia. Values for $M R, R Q$ and fidgeting were obtained from prospective studies conducted among the Pima Indians of Arizona.

BMI can be attributed to genetic factors (Table 1, Fig. 1; Stunkard et al. 1990; Price \& Gottesman, 1991; Allison et al. 1996). However, some have argued that the role of genes in determining BMI may be inflated in these studies, as the data were collected in developed countries where the environmental influences are likely to be consistent. Assuming that two-thirds of the variability in BMI is genetically determined, it is now important to determine how much of the genetic predisposition (or resistance) to obesity is related to energy metabolism (metabolic rate, spontaneous physical activity and fat oxidation) and how much is related to food intake.

\section{Metabolic predictors of weight gain}

The Pima Indians were studied in order to identify metabolic predictors of body weight gain and diabetes (Ravussin \& Swinburn, 1993). In these prospective studies body composition was assessed by hydrodensitometry, and measurements of energy metabolism were performed after a minimum of $3 \mathrm{~d}$ on a weight-maintenance diet provided at a clinical research centre. Total energy expenditure, $24 \mathrm{~h}$ respiratory quotient (RQ) and spontaneous physical activity were all simultaneously measured in a respiratory chamber as described previously (Ravussin et al. 1986). In both men and women, total energy expenditure increases with body

Table 1. Estimated heritability of obesity from studies of twins reared apart

\begin{tabular}{lcc}
\hline Study & Number of pairs & Heritability $\left(h^{2}\right)$ \\
\hline Stunkard et al. (1990) & 93 & $0.66 f, 0.7 \mathrm{~m}$ \\
Price \& Gottesman (1991) & 34 & 0.61 \\
Allison et al. (1996) & & \\
Finnish & 17 & 0.65 \\
Japanese & 10 & 0.73 \\
American & 26 & 0.85 \\
\hline
\end{tabular}

weight, although at any given weight the variability in energy expenditure is $500-700 \mathrm{kcal} / \mathrm{d}$. After adjustment for differences in fat-free mass, fat mass, age and sex, most of the variance was found to aggregate in families, indicating a genetic determinant of metabolic rate. Furthermore, the variability in metabolic rate is associated with such biological factors as body temperature (Rising et al. 1995) and the activity of the sympathetic nervous system (Spraul et al. 1993). Most importantly, after adjustment for the above covariates a low relative metabolic rate was associated with body-weight gain over a 3-4-year period of follow-up. The inverse relationship between weight change and adjusted $24 \mathrm{~h}$ energy expenditure had a coefficient of determination $\left(R^{2}\right)=0.16$ indicating that $16 \%$ of the variability in weight change was related to the variability in metabolic rate. However, as described below, part of this $16 \%$ may be related to variability in spontaneous physical activity. One can safely conclude that at least $12 \%$ of the variability in weight is caused by the variability in metabolic rate. We have previously emphasized that only prospective studies can identify metabolic predictors of weight gain, since there is a normalization of these factors in response to the development of obesity. Obesity is the price to pay for re-establishing an equilibrium (Ravussin \& Gautier, 1999).

The RQ is used to determine the relative amount of energy derived from carbohydrate and fat (Zurlo et al. 1990; Seidell et al. 1992). In studies of weight gain in Pima Indians over a period of 3 years, individuals with a high RQ were more likely to gain weight than those with a low RQ. The coefficient of determination of this relationship indicated that $5 \%$ of the variability in weight gain was related to the variability in RQ, adjusted for energy balance and percentage body fat. Respiratory quotient was also found to be a familial trait, and is probably, like metabolic rate, genetically determined (Zurlo et al. 1990). As with metabolic rate, the RQ is also related to such biological factors as the activity of the sympathetic nervous system. Similar results of high RQ predicting weight gain were 
obtained in older subjects (Seidell et al. 1992). In a dietary model of obesity, Pagliassotti et al. (1997) showed that, when placed on a high-fat diet, obesity-prone rats had a higher RQ than obesity-resistant rats. The authors observed that a high RQ is the major link with increased energy intake when animals are placed on a high-fat diet. Taken together, these results indicate that metabolic rate and RQ are two genetically determined traits which affect weight regulation in Pima Indians and probably in other populations.

Another component of $24 \mathrm{~h}$ energy expenditure is the energy cost of spontaneous physical activity which accounts for $8-15 \%$ of daily energy expenditure (Ravussin et al. 1986). Some of the $24 \mathrm{~h}$ energy expenditure variability is due to variability in the level of spontaneous physical activity (Ravussin et al. 1986; Zurlo et al. 1992). Most cross-sectional studies have shown a decrease in spontaneous physical activity in obese subjects. In longitudinal studies in Pima Indians, even in the confined environment of a respiratory chamber, spontaneous physical activity is a familial trait, and a low level of spontaneous physical activity was associated with subsequent weight gain in males (Zurlo et al. 1992). Consistent with these data, a recent overfeeding study found that a gain in fat mass was inversely related to the level of spontaneous physical activity (Levine et al. 1999). The authors call this activity non-exercise activity thermogenesis (NEAT).

\section{Factors underlying variability in body weight}

With the knowledge that approximately two-thirds of variance in BMI is genetically determined (Table 1; the remainder is due to 'sloth and gluttony'), we can divide the $67 \%$ into $12 \%$ for metabolic rate, $5 \%$ for RQ and an estimated $10 \%$ for spontaneous physical activity. This leaves another $40 \%$ related to factors not measured in these studies, i.e. food intake. The latter has been very difficult to measure in humans. One can use precise methods in a laboratory setting, but results are not reflective of everyday life, or crude methods under free-living conditions that are not accurate enough. Therefore new techniques, such as positron emission tomography or functional magnetic resonance imaging (MRI), will help to uncover the genetic components underlying hyperphagia. In a recent study (Tataranni et al. 1999) we showed that in healthy men neuronal activity increases in the prefrontal cortex and decreases in the hypothalamus, insular cortex, orbital frontal cortex, thalamus and hippocampal formation, in response to a single meal. Another study using functional MRI confirmed that lean subjects demonstrate an inhibition of signals in the area of the paraventricular and ventromedial nuclei of the hypothalamus (Matsuda et al. 1999). Importantly, these authors showed that this inhibitory response was markedly attenuated and delayed in obese subjects when compared with lean volunteers. Using PET scans, one of our most recent studies raises the possibility that the brain's responses to a meal in pre-frontal areas (often associated with the inhibition of inappropriate response tendencies) and in limbic/paralimbic areas (commonly associated with the regulation of emotions) may reflect changes in the central autonomic network, which may be different between obese and lean subjects (Gautier et al.
1999, unpublished results). Such techniques, applied to post-obese subjects as well as patients suffering from eating disorders, will help identify the neurological pathways involved in hyperphagia, often found in obese subjects.

\section{The search for obesity genes}

Over the past 5 years genetic linkage studies have focused increasingly on complex traits such as obesity. Genomewide scans have been completed in Mexican Americans (Comuzzie et al. 1997); Pima Indians (Hanson et al. 1998; Norman et al. 1998); a diverse population of whites and blacks (Lee et al. 1999); French Canadian families (Pérusse et al. 1999); and French families (Hager et al. 1998). From all these studies, major loci linked to obesity have been found on chromosomes 2, 5, 10, 11 and 20. Those areas of the genome will be studied further to possibly clone obesity susceptibility genes.

The Québec group (Pérusse et al. 1999) provides an annual update of the human obesity gene map. From association and linkage studies, the authors claim that putative loci affecting obesity-related phenotypes are found on all except chromosome $\mathrm{Y}$ of the human genome. It also seems that the number of genes and other markers that have been associated or linked with human obesity is increasing very rapidly, and now approaches 200 .

With the upcoming partial publication of the Human Genome, it is likely that our understanding of the genetic basis and the identification of novel genes involved in obesity will be greatly improved. New pathways in the etiology of obesity will be uncovered, and in the more distant future individual identification of genetic variants will be possible, making individually targeted therapies available.

\section{Acknowledgements}

The authors wish to express their gratitude to the entire staff of the CDNS for their commitment to clinical studies of the etiology of type-2 diabetes and obesity among Pima Indians. Most of all, we thank the Pima Indian volunteers from the Gila River Indian Communities and their leaders: without their willing cooperation and participation these studies would not have been possible.

\section{References}

Allison DB, Kaprio J, Korkeila M, Koskenvuo M, Neale MC \& Hayakawa K (1996) The heritability of body mass index among an international sample of monozygotic twins reared apart. International Journal of Obesity Related Metabolic Disorders 20, 501-506.

Bouchard C (1994) In The Genetics of Obesity [Claude Bouchard, editor]. Boca Raton, FL: CRC Press.

Comuzzie AG, Hixson JE, Almasy L, Mitchell BD, Mahaney MC, Dyer TD, Stern MP, MacCluer JW \& Blangero J (1997) A major quantitative trait locus determining serum leptin levels and fat mass is located on human chromosome 2. Nature Genetics $\mathbf{1 5}$, 273-276.

Egger G \& Swinburn B (1997) An 'ecological' approach to the obesity pandemic. British Medical Journal 315, 477-480.

Flegal KM, Carroll MD, Kuczmarski RJ \& Johnson CL (1998) 
Overweight and obesity in the United States: prevalence and trends 1960-1994. International Journal of Obesity 22, $39-47$.

Hager J, Dina C, Francke S, Dubois S, Houari M, Vatin V, Vaillant E, Lorentz N, Basdevant A, Clement K, Guy-Grand B \& Froguel $\mathrm{P}$ (1998) A genome-wide scan for human obesity genes reveals a major susceptibility locus on chromosome 10. Nature Genetics 20, 304-308.

Hanson RL, Ehm MG, Pettit DJ, et al. (1998) An autosomal genomic scan for loci linked to type II diabetes mellitus and body-mass index in Pima Indians. American Journal of Human Genetics 63, 1130-1138.

Lee JH, Reed DR, Li WD, Xu W, Joo EJ, Kilker RL, Nanthakumar E, North M, Sakul H, Bell C \& Price RA (1999) Genome scan for human obesity and linkage to markers in 20q13. American Journal of Human Genetics 64, 196-209.

Levine JA, Eberhardt NL \& Jensen MD (1999) Role of nonexercise activity thermogenesis in resistance to fat gain in humans. Science 283, 212-214.

Lichtman SW, Pisarska K, Berman ER, et al. (1992) Discrepancy between self-reported and actual caloric intake and exercise in obese subjects. New England Journal of Medicine 327, 1893-1897.

Matsuda M, Liu Y, Mahankali S, Pu Y, Mahankali A, Wang J, DeFronzo RA, Fox PT \& Gao JH (1999) Altered hypothalamic function in response to glucose ingestion in obese humans. Diabetes 48, 1801-1806.

Norman R, Tataranni P, Pratley R, et al. (1998) Autosomal genomic scan for loci linked to obesity and energy metabolism in Pima Indians. American Journal of Human Genetics 62, 659668.

Pagliassotti MJ, Gayles EC \& Hill JO (1997) Fat and energy balance. Annals of the New York Academy of Science 827, 431448.

Pérusse L, Chagnon YC, Weisnagel J \& Bouchard C (1999) The human obesity gene map: the 1998 update. Obesity Research 7, 111-29.

Price RA \& Gottesman II (1991) Body fat in identical twins reared apart: roles for genes and environment. Behavior Genetics 21, $1-7$.

Ravussin E (1995) Obesity in Britain: rising trend may be due to 'pathoenvironment'. Lancet 311, 1569.

Ravussin E \& Gautier J-F (1999) Metabolic predictors of weight gain. International Journal of Obesity 23, 37-41.
Ravussin E \& Swinburn BA (1992) Pathophysiology of obesity. Lancet 340, 404-408.

Ravussin E \& Swinburn BA (1993) Metabolic predictors of obesity. Cross-sectional versus longitudinal data. International Journal of Obesity 17, S28-S31.

Ravussin E, Lillioja S, Anderson TE, Christin L \& Bogardus C (1986) Determinants of 24-hour energy expenditure in man. Journal of Clinical Investigation 78, 1568-1578.

Rising R, Fontvieille AM, Larson DE, Spraul M, Bogardus C \& Ravussin E (1995) Racial difference in body core temperature between Pima Indian and Caucasian men. International Journal of Obesity Related Metabolic Disorders 19, 1-5.

Rosenbaum M, Leibel RL \& Hirsch J (1997) Obesity. New England Journal of Medicine 337, 396-407.

Schoeller DA \& Field CR (1991) Human energy metabolism, what have we learned from the doubly labeled water method? Annual Review of Nutrition 11, 355-373.

Seidell JC, Muller DC, Sorkin JD \& Andres R (1992) Fasting respiratory exchange ratio and resting metabolic rate as predictors of weight gain: the Baltimore Longitudinal Study of Aging. International Journal of Obesity 16, 667-674.

Spraul M, Ravussin E, Fontvieille MA, Rising R \& Larson DE (1993) Reduced sympathetic nervous activity. A potential mechanism predisposing to body weight gain. Journal of Clinical Investigation 92, 1730-1735.

Stunkard AJ, Harris JR, Pedersen NL, McClearn GE (1990) The body-mass index of twins who have been reared apart. New England Journal of Medicine 322, 1483-1487.

Tataranni PA, Gautier JF, Chen K, Uecker A, Bandy D, Salbe AD, Pratley RE, Lawson M, Reiman EM \& Ravussin E (1999) Neuroanatomical correlates of hunger and satiation in humans using positron emission tomography. Proceedings of the National Academy of Sciences, USA 96, 4569-4574.

Wolf AM \& Colditz GA (1998) Current estimates of the economic cost of obesity in the United States. Obesity Research 6, 97-106.

Zurlo F, Lillioja S, Esposito-Del Puente A, Nyomba BL, Raz I, Saad MF, Swinburn BA, Knowler WC, Bogardus C \& Ravussin E (1990) Low ratio of fat to carbohydrate oxidation as predictor of weight gain: study of 24-h RQ. American Journal of Physiology 259, E650-E657.

Zurlo F, Ferraro RT, Fontvieille AM, Rising R, Bogardus C \& Ravussin E (1992) Spontaneous physical activity and obesity: cross-sectional and longitudinal studies in Pima Indians. American Journal of Physiology 263, E296-E300. 